\title{
ERRATA
}

\section{Erratum: Spectral properties of backward stimulated scattering in liquid carbon disulfide [JETP 85, 850-856 (November 1997)]}

\author{
Guang S. He, Yiping Cui, and Paras N. Prasad \\ Photonics Research Laboratory, State University of New York at Buffalo, Buffalo, New York 14260-3000, \\ USA
}

[S1063-7761(98)02902-3]

The correct caption of Fig. 4 should read as “ "... at various attenuation ratios: 1/180 (a), ..."

The correct caption of Fig. 5 should read as "pumped by the $\sim 0.1 \mathrm{~cm}^{-1}$-wide 532 -nm line..."

The correct Ref. 11 should be: E. J. Miller and R. W. Boyd, Int. J. Nonlinear Opt. Phys. 4, 765 (1992). 